\title{
AVALIAÇÃO DA RECUPERAÇÃO DE ÁGUA A PARTIR DA FILTRAGEM DO REJEITO DE MINÉRIO DE NÍQUEL*
}

Tatiana Salviano Gadelha ${ }^{1}$ Silvia Cristina Alves França ${ }^{2}$

\section{Resumo}

Rejeitos de mineração descartados na forma de polpa possuem, geralmente, grande quantidade de água e reutilizá-la no processo, por meio de operações de desaguamento mais eficientes é de grande importância para a implementação de projetos de menor impacto ambiental. O presente trabalho visa estudar as operações envolvidas no desaguamento de um rejeito de níquel, com o objetivo de principalmente a maximizar a recuperação de água de processo. Para tanto, foram avaliados: a influência da concentração de sólidos, uso e dosagem de floculante, pressão no filtro, o processo de filtração com e sem prensagem e a influência destas variáveis na umidade da torta e na recuperação de água. Os resultados mostraram que quanto maior a dosagem de floculante menor é a recuperação de água na filtragem; por outro lado, quanto maiores a concentração de sólidos e a pressão, maior a recuperação de água. Verificou-se a importância do uso da prensagem para maximizar a recuperação da água contida no sedimento, sendo possível comprovar que o rejeito de níquel floculado e filtrado com $\Delta \mathrm{P}$ de 6 bar com o uso de prensagem promoveu a recuperação de até $77 \%$ de água.

Palavras-chave:Rejeitos Minerais; Floculação; Filtragem; Reuso de água de processo.

\section{WATER RECOVERY ASSESSMENT FROM FILTRATION OF NICKEL ORE TAILINGS}

\begin{abstract}
Water is a rare resource and mineral tailings disposed as slurry have large amounts of water. Thus, reuse of water it in the process through more efficient dewatering operations has a great importance for the implementation of lower impact to the environment projects. This work aims to study the operations involved in dewatering of a nickel ore tailings, mainly aiming maximizing process water recovery. Thus, it was evaluated: the influence of solids concentration, flocculant dosage, filtration pressure, the use of squeeze in the filtration process and the influence of these variables on the cake moisture and water recovery. The results showed that the higher dose of flocculant, water recovery is lower. Was observed the importance of using mechanical pressure to maximize the water recovery contained in the sediment, It is possible to prove that the nickel ore tailing flocculated and filtered with $\Delta \mathrm{P}=6$ bar using mechanical pressure (pressing) promoted the recovery to $77 \%$ of water.
\end{abstract}

Keywords: Mineral tailings; Flocculation; Filtration; Water reuse.

1 Engenheira Química, Msc, Bolsista PCl, Coordenação de Processos Minerais, CETEM - Centro de Tecnologia Mineral, Rio de Janeiro - RJ, Brasil.

2 Engenheira Química, Dsc. Tecnologista Sênior, Coordenação de Processos Minerais, CETEM Centro de Tecnologia Mineral, Rio de Janeiro - RJ, Brasil. 


\section{INTRODUÇÃO}

A água é um recurso escasso para as plantas de processamento de minério em muitas partes do mundo. $\mathrm{O}$ alto custo da água $\mathrm{e}$, em alguns casos, sua indisponibilidade, aumentam os custos de beneficiamento do minério, podendo chegar a inviabilizar o seu aproveitamento.

Rejeitos descartados na forma de polpa possuem grandes quantidades de água. Assim, reutilizar a água de processo por meio de operações de desaguamento mais eficientes é de grande importância para a implementação de projetos de menor impacto ao meio ambiente.

No Brasil, os rejeitos de beneficiamento são normalmente dispostos em forma de polpa, em barragens. Entretanto, no mundo há uma forte tendência para o adensamento de rejeitos uma vez que a disposição de polpas de alta densidade, pastas minerais ou tortas apresenta vantagens consideráveis e representa alternativas às práticas convencionais (Guimarães, 2011).

A agregação de partículas finas é uma saída utilizada na separação destas em meio líquido, uma vez que a sedimentação de sólidos finos em suspensão requer muito tempo, exigindo a utilização de grandes áreas para construção de barragens. Esta situação também é ampliada pela formação de redes de partículas estáveis (géis). Tais estruturas aprisionam um volume significativo de água que não está disponível para reuso. Nesse contexto, se faz indispensável o uso de reagentes, como coagulantes ou polímeros floculantes, que permitem a adesão de uma partícula diretamente à outra, dando origem à estrutura do floco. A quantidade e o tipo de polímero floculante utilizado é função das características físico-químicas de superfície das partículas, bem como do seu tamanho, que reflete diretamente na área superficial. Além das características dos floculantes, os aspectos físicos do rejeito, como distribuição granulométrica, morfologia das partículas e mineralogia têm influência nas interações entre o material particulado e a água, durante os processos de agregação (Oliveira et al., 2004; Wang et al, 2014).

No processo de espessamento, forma-se um sedimento saturado em água e, na maioria das vezes, é necessário expelir essa água em excesso para maior redução de volume e aumento da resistência mecânica do sedimento, satisfazendo as especificações regulatórias para deposição segura do rejeito (Wang et al, 2014). Uma operação unitária adicional utilizada no desaguamento de polpas minerais é a filtração com formação de torta, em que o produto sólido resultante - a torta - com elevada concentração de sólidos, pode então ser transportada ou descartada mais facilmente (Qi et al, 2011) e o filtrado, reutilizado como água de processo.

Os filtros mais comumente utilizados na indústria são os que funcionam por pressão ou vácuo. A filtragem sob pressão é caracterizada pela aplicação de uma pressão positiva na polpa, sendo uma das principais vantagens dessa operação a produção de tortas com menor teor de umidade, em comparação com outras tecnologias de filtragem (Nery, 2013).

As etapas de formação da torta em uma operação de filtragem sob pressão são apresentadas na Figura 1: em $\mathrm{t}=0$ a polpa entra em contato com filtro e é submetida a uma determinada queda de pressão $\Delta \mathrm{P}$. Em $\mathrm{t}_{1}$ inicia-se o escoamento da água através do meio filtrante, dando início a etapa de formação da torta. Quando $\mathrm{t}=\mathrm{t}_{1}$ a película de água na superfície da torta desaparece e a água está presente apenas nos espaços vazios entre as partículas agregadas. A filtragem continua até o tempo $t_{2}$, que é a etapa de desaguamento, onde há a máxima compactação das partículas e remoção de água, que está relacionada à redução da umidade da torta. 
Quando não há mais água entre os poros das partículas, ocorre a descarga de ar através dos poros.
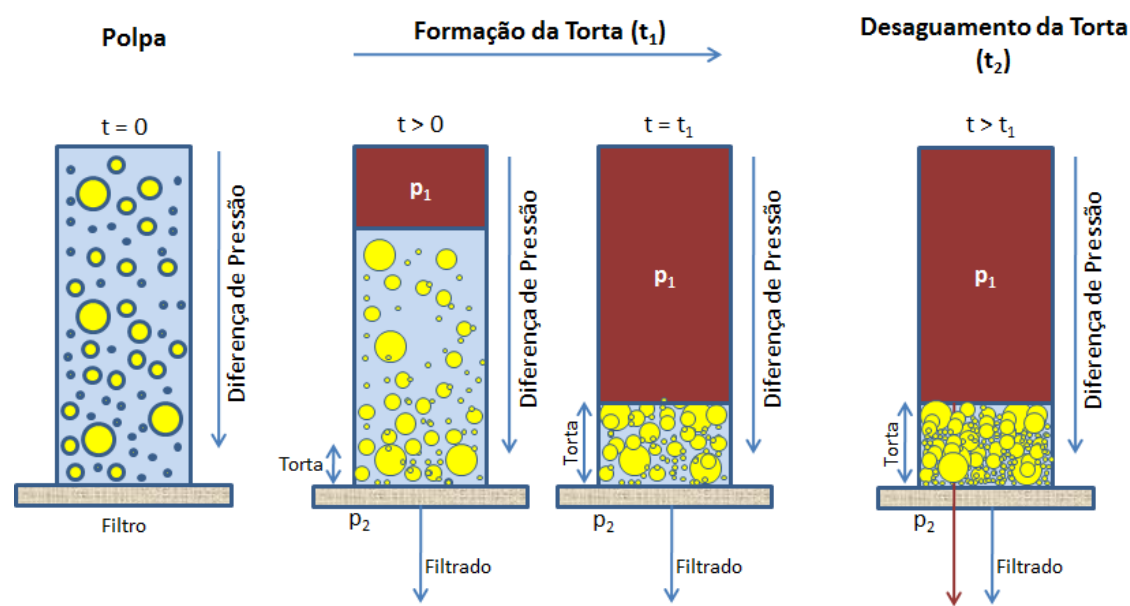

Figura 1: Etapas de formação da torta de filtração (Gadelha e França, 2015).

A presença de floculantes afeta o desempenho da filtragem. Quanto maior a cadeia polimérica do floculante, maior será a quantidade de água aprisionada no interior do floco formado, dificultando o máximo desaguamento na filtração. Por isso, usualmente são utilizados polímeros floculantes de baixo peso molecular, que formam flocos relativamente pequenos, e com pouca água retida. Caso haja necessidade de utilizar floculantes de alto peso molecular, é necessário cisalhar o sedimento antes da filtragem, a fim de quebrar os flocos para a liberação da água retida no interior da sua estrutura (Oliveira, 2004).

Durante a filtração, a vazão de filtrado depende da diferença de pressão, da resistência do meio filtrante e da torta. A taxa de fluxo volumétrico do filtrado pode ser descrita pela Equação 1:

$$
\frac{t}{V}=\frac{\mu \alpha W}{2 \Delta P A^{2}} V+\frac{\mu R_{m}}{\Delta P A}
$$

Onde, $\mathbf{V}$ é o volume do filtrado $\left(\mathrm{m}^{3}\right)$, $\mathbf{t}$ é o tempo de filtração (s), A é a área do filtro $\left(\mathrm{m}^{2}\right), \Delta \mathbf{P}$ é a queda de pressão $(\mathrm{Pa}), \boldsymbol{\mu}$ é a viscosidade do filtrado (Pa.s), aé a resistência específica da torta $(\mathrm{m} / \mathrm{kg})$, w é a concentração de sólidos $\left(\mathrm{kg} / \mathrm{m}^{3}\right)$ e $\mathbf{R m}$ é a resistência ao meio filtrante.

A resistência específica à filtração mede a filtrabilidade da suspensão tal como determinado pelas características da polpa. Quando as partículas finas são floculadas para formar flocos maiores (agregados) a filtrabilidade é significativamente melhorada (Xu, 2008).

Assim, o objetivo deste trabalho é estudar as operações envolvidas no desaguamento de um rejeito de níquel, visando à produção de concentrados minerais com alto teor de sólidos e recuperação de água de processo. Para tanto, pretende-se: i) averiguar a influencia da dosagem do floculante $R$ na filtração do rejeito de níquel; ii) avaliar o processo de filtração com e sem prensagem e a sua influência na umidade da torta e na recuperação de água; iii) estudar a filtração do sedimento formado, relacionando a influência da concentração de sólidos, dosagem dofloculante e pressão no filtro na umidade final da torta; iv) determinar a recuperação de água nas condições operacionais avaliadas. 


\section{MATERIAIS E MÉTODOS}

\subsection{Amostragem}

Foi utilizado um rejeito do beneficiamento de minério sulfetado de níquel. Foram separados 40 quilos de amostra, que foi seca em estufa visando facilitar a desagregação do material e remoção da umidade. Em seguida, a amostra foi desagregada em peneira com abertura de $149 \mu \mathrm{m}$ e disposta em pilha alongada, sendo quarteada em alíquotas de 100 gramas para os ensaios de laboratório.

\subsection{Ensaios de Sedimentação}

Neste estudo a polpa foi floculada pelo polímero comercial $\mathrm{R}$ (aniônico), utilizado na forma de solução polimérica a $0,5 \mathrm{~g} / \mathrm{L}$, nas dosagens de 50 e $200 \mathrm{~g} / \mathrm{t}$.

Os testes de sedimentação foram realizados em equipamento jar test, com polpas previamente preparadas adicionadas ao equipamento. Após um tempo de agitação de 3 minutos a $300 \mathrm{rpm}$, o floculante foi adicionado à polpa em pH natural, de 6,8. Em seguida, a polpa foi condicionada por 1 minuto a 300 rpm e 2 minutos a 150 rpm, totalizando 3 minutos de agitação, para permitir o contato entre as partículas e o reagente e, consequentemente, o crescimento dos flocos. Após este período, foi cessada a agitação e a polpa foi mantida em repouso para sedimentação durante 1 hora.

\subsection{Filtragem}

Após a sedimentação, o liquido sobrenadante foi sifonado, concentrando o sedimento $(50,60$ e $70 \%)$ que em seguida foi submetido a cisalhamento em jartest por 1 minuto a $300 \mathrm{rpm}$, objetivando liberar a água aprisionada na estrutura dos flocos antes da filtragem.

O diagrama de blocos da Figura 2 mostra a metodologia utilizada no trabalho.

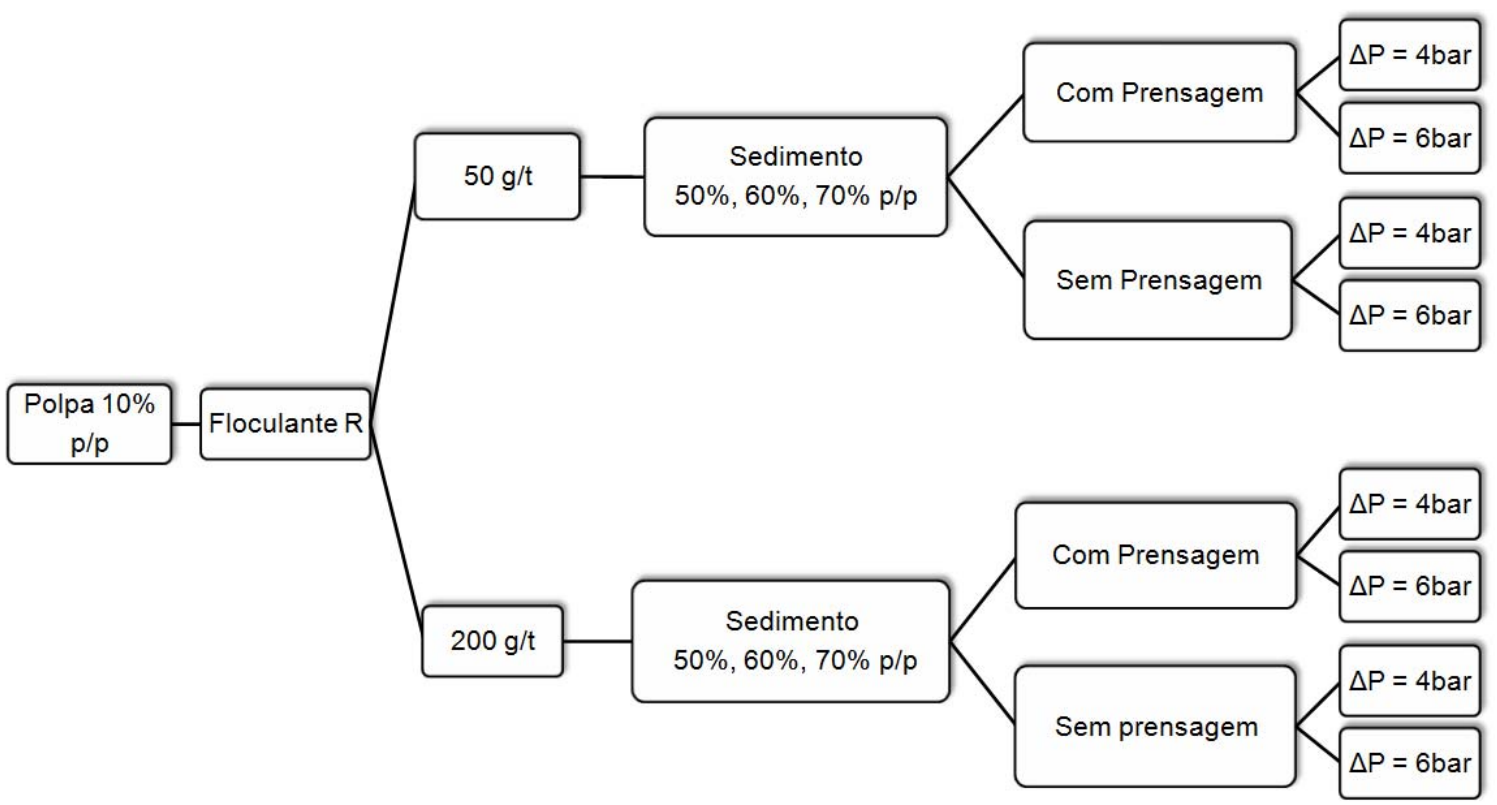

Figura 2: Metodologia utilizada no processo de filtração da polpa floculada e espessada. 
Os ensaios de filtragem foram realizados no equipamento Filtratest ${ }^{\mathrm{TM}}$ (Bokela), com área de filtragem de $19,63 \mathrm{~cm}^{2}$. Foi utilizado um tecido filtrante de polipropileno com fios de multifilamentos, com permeabilidade ao ar de $1,5-5 \mathrm{~m}^{3} / \mathrm{min} / \mathrm{m}^{2}$; adotou-se 0 tempo de desaguamento da torta de 120 segundos para todos os testes. Foram comparados os processos de filtragem sob pressão com e sem prensagem. $O$ desempenho dos polímeros foi avaliado com base na umidade final da torta de filtração.

A Figura 3 mostra os dispositivos onde é formada a torta e o que promove a prensagem.

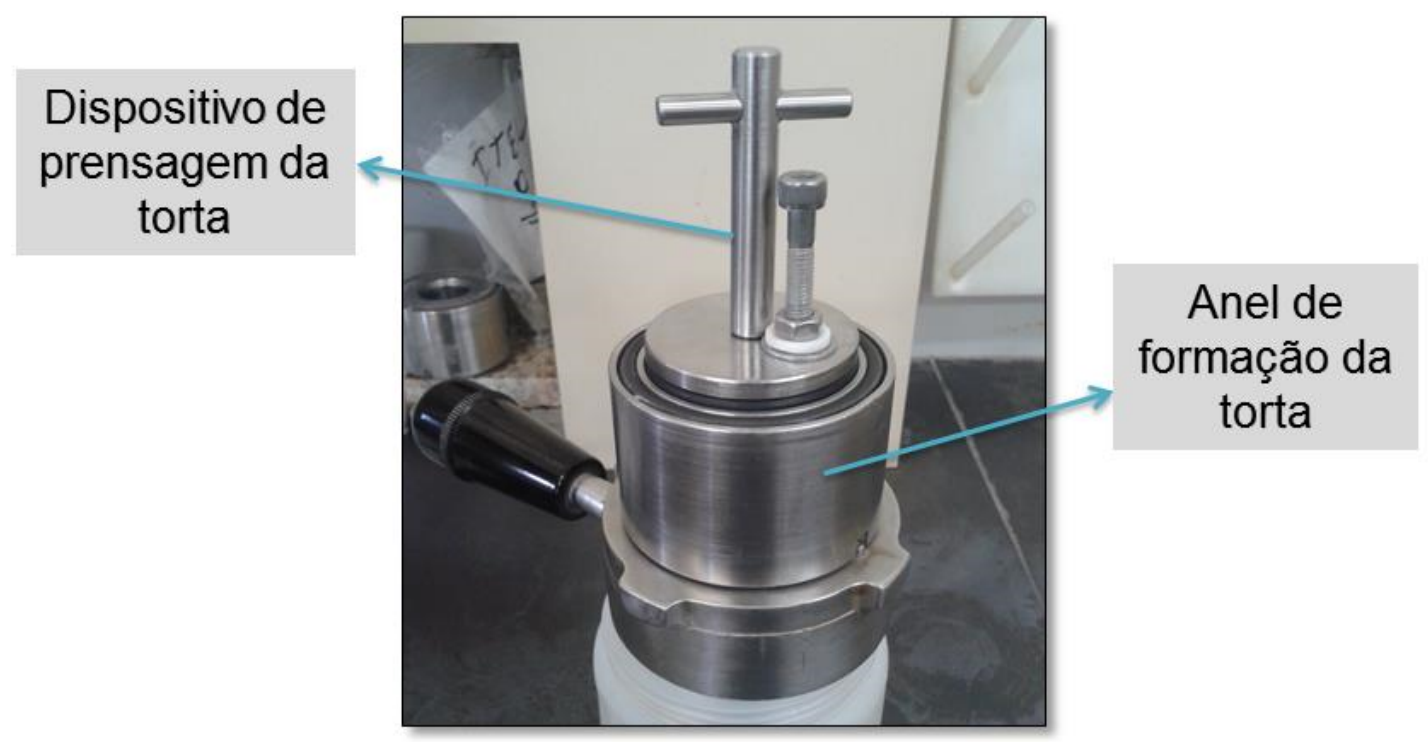

Figura 3: Dispositivo de prensagem da torta.

\section{RESULTADOS E DISCUSSÃO}

Os resultados de umidade da torta de filtração nas condições descritas anteriormente são exibidos na Figura 3.

A presença de floculante na polpa espessada afeta significativamente a filtrabilidade do sedimento. É sabido que a dosagem de floculante impacta o processo de floculação e as propriedades dos flocos formados, uma vez que normalmente uma "dosagem ótima", que é a quantidade ideal de polímero que os sólidos necessitam para flocular. Quando é adicionado floculante em excesso, o polímero não é completamente absorvido. Flocos de tamanho grande são formados, com grande quantidade de água aprisionada dentro dos flocos, resultando em menor taxa de sedimentação e densidade de sedimentos. Por conseguinte, a dosagem de polímero pode ter um efeito considerável sobre variáveis da operação de filtragem, como a resistência de filtração e a umidade da torta (Xu, 2008).

Avaliando o efeito da dosagem do polímero $\mathrm{R}$ na variável umidade, é possível notar na Figura 3 (a), (b), (c) e (d) que, para a dosagem de $50 \mathrm{~g} / \mathrm{t}$ (4 e 6 bar; sem prensagem), a umidade final da torta é menor que a observada para $200 \mathrm{~g} / \mathrm{t}$.

Apesar do prévio cisalhamento do sedimento, que visou a quebra dos flocos para liberar água de sua estrutura, foi possível verificar que o tempo de agitação não foi suficiente para aproximar os resultados obtidos com $50 \mathrm{~g} / \mathrm{t}$ de floculante aos obtidos com a dosagem de $200 \mathrm{~g} / \mathrm{t}$, na pressão de 4 bar. Para a pressão de 6 bar, essa diferença foi menor, uma vez que o aumento da pressão possibilitou maior 
compressão da torta, promovendo maior expulsão de água da estrutura do floco, aumentando eficiência do desaguamento.

Entretanto, esta tendência não foi observada na filtragem com prensagem, uma vez que esta variável promove a maximização da remoção de água da estrutura do floco, minimizando o efeito da dosagem de floculante e da concentração de sólidos na umidade da torta.

Para a variação na concentração de sólidos, observou-se influência significativa apenas para filtragem com $\Delta \mathrm{P}=4$ bar, conforme apresentado na Figura 4.

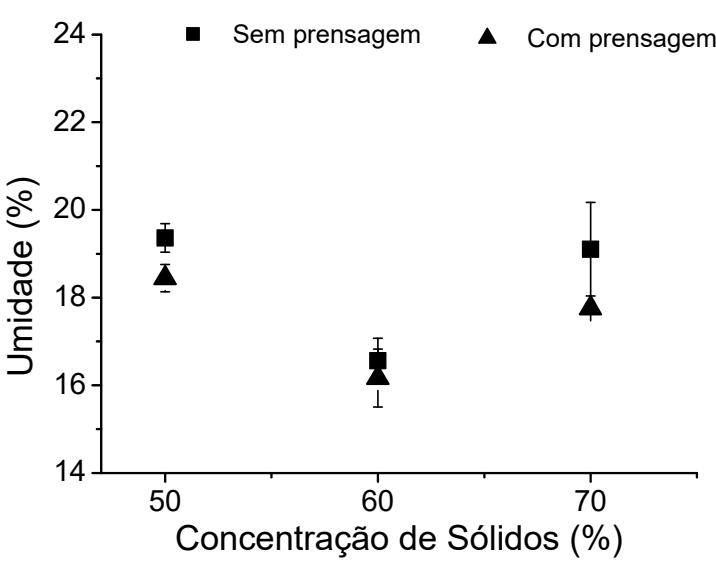

(a)

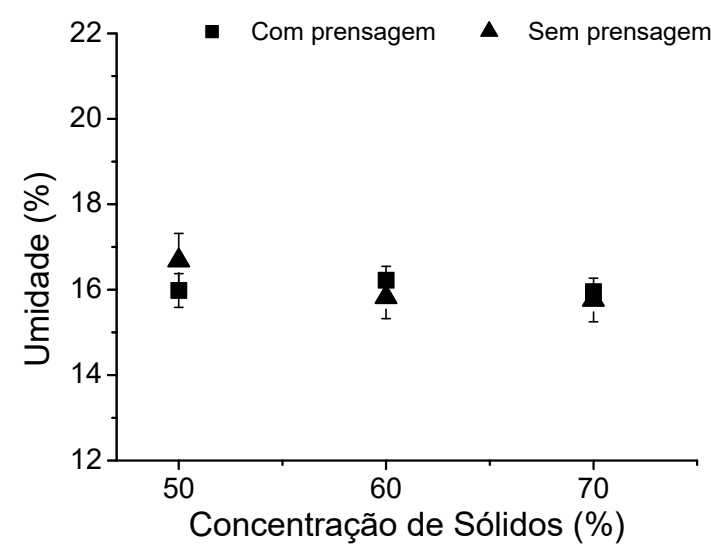

(c)

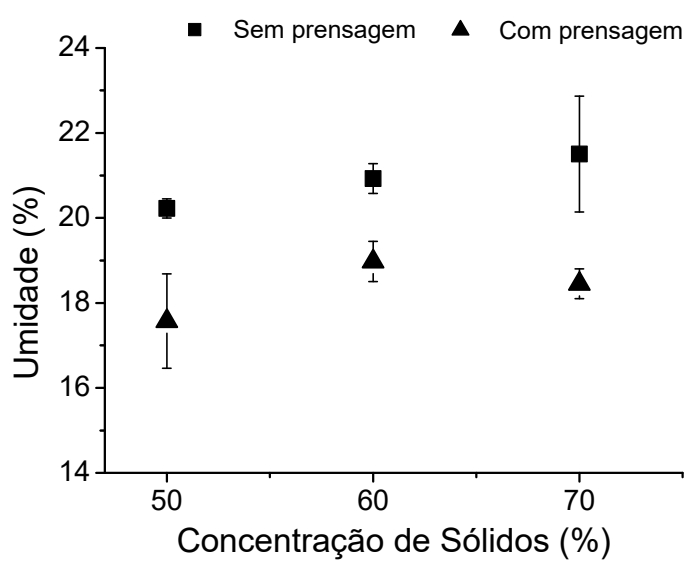

(b)

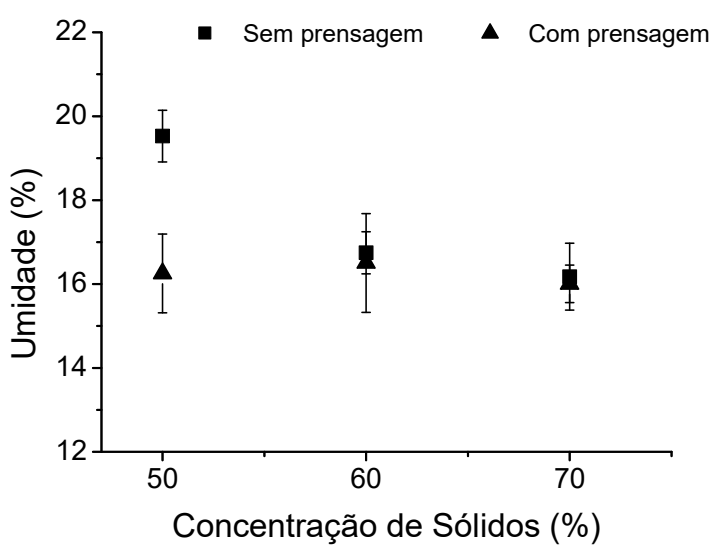

(d)

Figura 4: Umidade final da torta de acordo com a concentração de sólidos da polpa espessada: (a) $\Delta \mathrm{P}=4$ bar e dosagem de $50 \mathrm{~g} / \mathrm{t}$; (b) $\Delta \mathrm{P}=4$ bar e dosagem de $200 \mathrm{~g} / \mathrm{t}$; (c) $\Delta \mathrm{P}=6$ bar e dosagem de $50 \mathrm{~g} / \mathrm{t} ;(\mathrm{d}) \Delta \mathrm{P}=6$ bar e dosagem de $200 \mathrm{~g} / \mathrm{t}$.

A Figura 5 e Figura 6 exibem a recuperação de água no processo de filtração. Nos gráficos observa-se que para as dosagens avaliadas, há aumento na recuperação de água com o aumento da pressão no filtro. Também é possível constatar que quanto maior é a concentração de sólidos no sedimento, maior é a recuperação de água.

Comparando os gráficos das Figuras 5 e 6 nota-se que a redução da umidade é aumentada quando aplicada prensagem adicional na torta. 
Em relação a dosagem do floculante $R$, é possível observar que o aumento na dosagem reduziu a recuperação da água contida no sedimento. Isso ocorre uma vez que flocos maiores $(200 \mathrm{~g} / \mathrm{t})$ aprisionam mais água em sua estrutura; menciona-se, ainda, o aumento na viscosidade da polpa que também dificulta as operações de separação sólido-líquido, fazendo com que a máxima retirada de água seja possível apenas com o emprego de mais energia. Essa tendência foi observada principalmente para $\Delta \mathrm{P}=4$ bar, com e sem prensagem; para $\Delta \mathrm{P}=6$ bar, este efeito tende a ser minimizado.

Baixos valores de umidade do resíduo seco apontam para a possibilidade de disposição do rejeito sólido (torta) que pode satisfazer os órgãos reguladores. Este tipo de disposição é conhecido como empilhamento a seco. Neste caso, a disposição é considerada segura e o resíduo pode ser obtido com características que torna possível a disposição como material "não perigoso" (Nery, 2013).

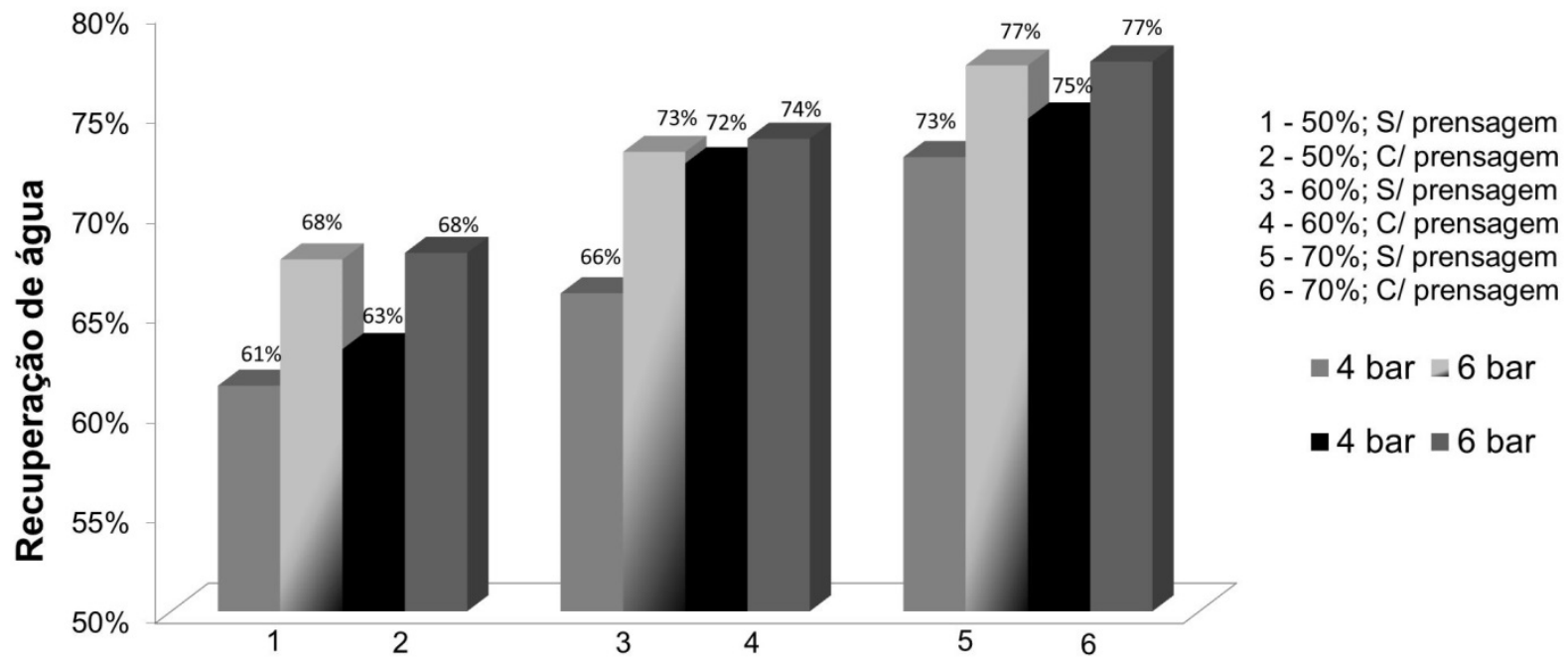

Figura 5: Recuperação de água na filtragem de sedimentos floculados na dosagem de $50 \mathrm{~g} / \mathrm{t}$.

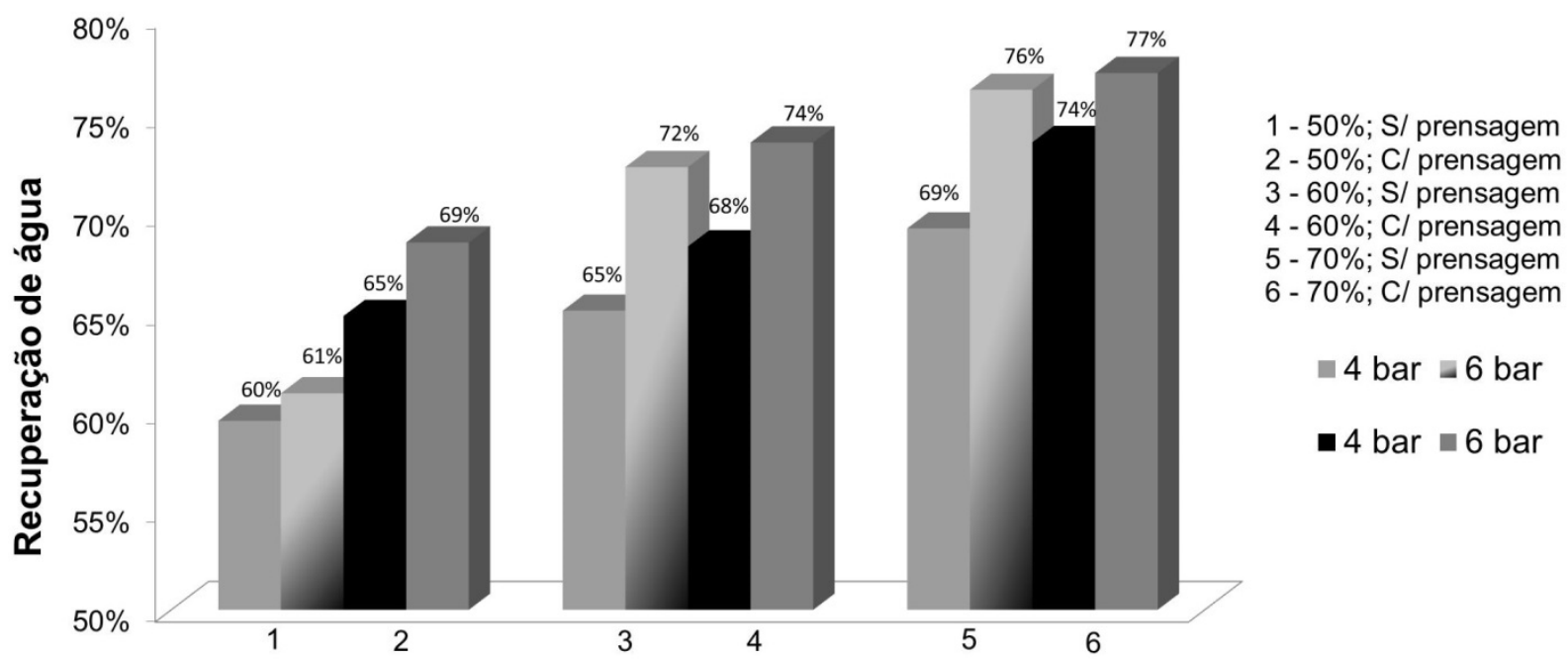

Figura 6: Recuperação de água na filtragem sedimentos floculados na dosagem de $200 \mathrm{~g} / \mathrm{t}$.

A Figura 7 mostra o ganho na recuperação de água conseguido com o uso de pressão mecânica na torta. É possível confirmar que para maior dosagem de 
floculante a recuperação de água com a prensagem é mais expressiva. Também é possível observar que para a polpa floculada com floculante na dosagem de $50 \mathrm{~g} / \mathrm{t}$ a diferença entre a recuperação de água com e sem prensagem é bem menor que a verificada quando usado o floculante na dosagem de $200 \mathrm{~g} / \mathrm{t}$. Este fato ocorre, pois os flocos formados por floculantes em baixa dosagem são menores e aprisionam menos água em sua estrutura. Então, possivelmente, o cisalhamento do sedimento antes da filtragem foi suficiente para liberar a água contida na estrutura do floco, e a pressão mecânica foi menos efetiva quando utilizada no desaguamento do sedimento floculado com polímero na dosagem de $200 \mathrm{~g} / \mathrm{t}$.

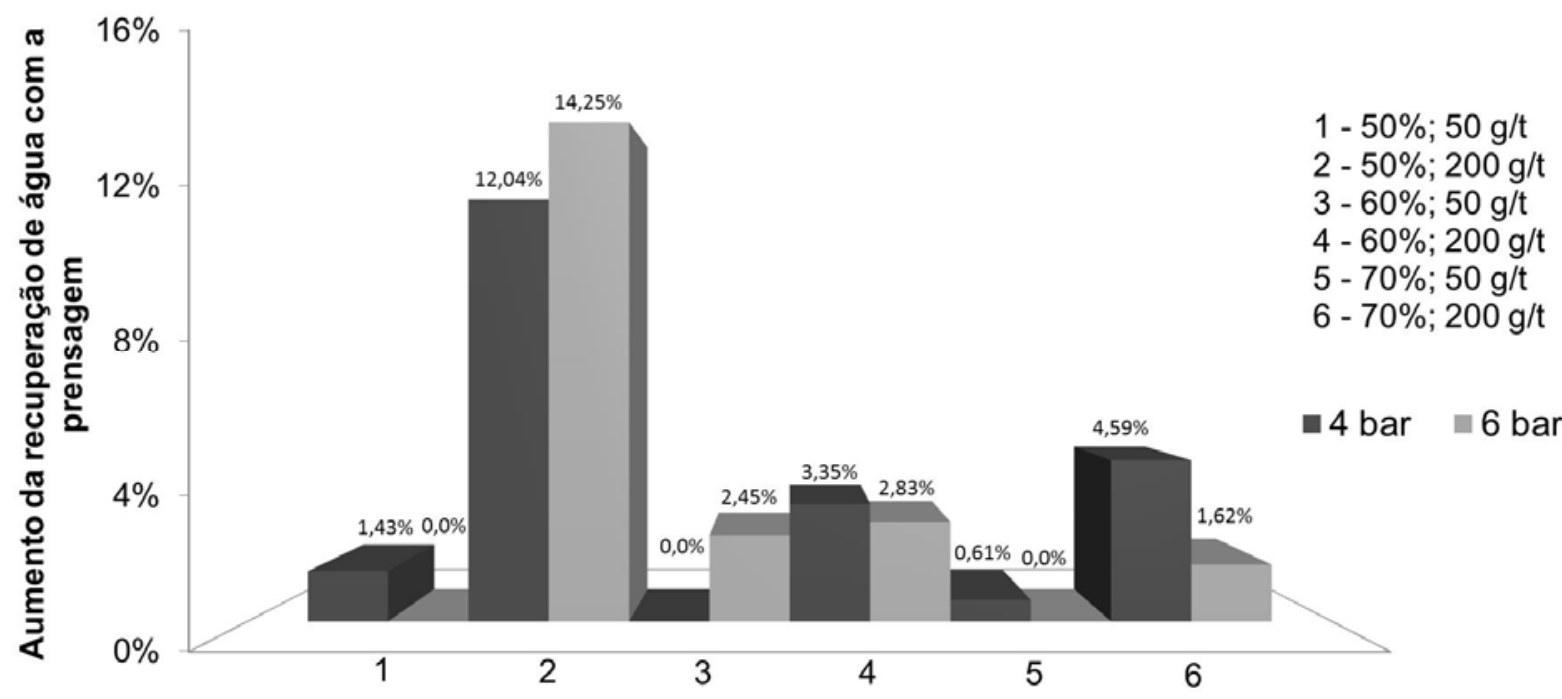

Figura 7: Recuperação de água com o uso de prensagem.

\section{CONCLUSÃO}

Neste estudo foi possível comprovar que, nas mesmas condições de cisalhamento do floco, quanto maior a dosagem de floculantemenor é a recuperação de água, causada pela maior retenção de água na estrutura do floco. Os resultados também apontamo aumento na recuperação de água com o aumento da pressão no filtro. Também é possível constatar que para maiores concentrações de sólidos no sedimento, maior é a recuperação de água.

Esta análise mostra a importância do uso da pressão mecânica para maximizar a recuperação da água contida no sedimento, principalmente quando a concentração de sólidos do sedimento que alimenta o filtro não puder ser muito elevada e/ou quando a dosagem de floculante utilizada no espessador for alta.

Por fim, foi possível comprovar que o rejeito de níquel floculado com $50 \mathrm{~g} / \mathrm{t}$ do polímero $\mathrm{R}$ e filtrado a $\Delta \mathrm{P}=6$ bar, com o uso de prensagem, promoveu a recuperação de até $77 \%$ de água contida no sedimento espessado. Esses resultados apontam, ainda para a possibilidade de disposição do rejeito sólido (torta) de baixa umidade em pilhas, que é uma forma de disposição ambientalmente mais amigável.

\section{Agradecimentos}

Ao CNPq pela bolsa concedida através do Programa PCl/CETEM/MCTI. 


\section{REFERÊNCIAS}

1 GUIMARÃES, N. C. Filtragem de rejeitos de minério de ferro visando a sua disposição em pilhas. Dissertação de Mestrado, Escola de Engenharia, Universidade Federal de Minas Gerais, 2011. Belo Horizonte, MG, Brasil.

2 GADELHA, T. S.; FRANÇA, S. C. A.. Polymer Assessment for Dewatering and Filtration of Nickel Ore Tailings. $4^{\text {th }}$ International Seminar on Environmental Issues in Mining, 2015. Lima, Peru.

3 HOGG, R Flocculation and dewatering. In International Journal of Mineral Processing, 2000. Vol. 58, p. 223-236.

4 OLIVEIRA, M.L.M.; LUZ, J.A.M.; LACERDA, C.M.M. Espessamento e filtragem. Universidade Federal de Ouro Preto, 2004. Ouro Preto, Brasil, p. 4-42.

5 NERY, Kellen Dias.Caracterização geotécnica e avaliação da compactação de um resíduoda produção de alumina (lama vermelha) desaguado por filtro prensa Dissertação de Mestrado, Escola de Engenharia, Universidade Federal de Minas Gerais, 2013. Belo Horizonte, MG, Brasil.

6 QI, Y., THAPA, Khagendra B., HOADLEY, Andrew F.A. Application of filtration aids for improving sludge dewatering properties $-A$ review. Chemical Engineering Journal, 2011. Vol. 58, p.373 - 384.

7 WANG, C., HARBOTTLE, D., et al. Current state of fine mineral tailings treatment: A critical review on theory and practice. In Minerals Engineering, 2014. Vol. 58,p. 113131.

8 XU, Yuming; DABROSA, Tadek; KAN, Jianmin. Filterability of oil sands tailings. Process Safety and Environment Protection, 2008. Vol. 86, p. 268 - 276. 